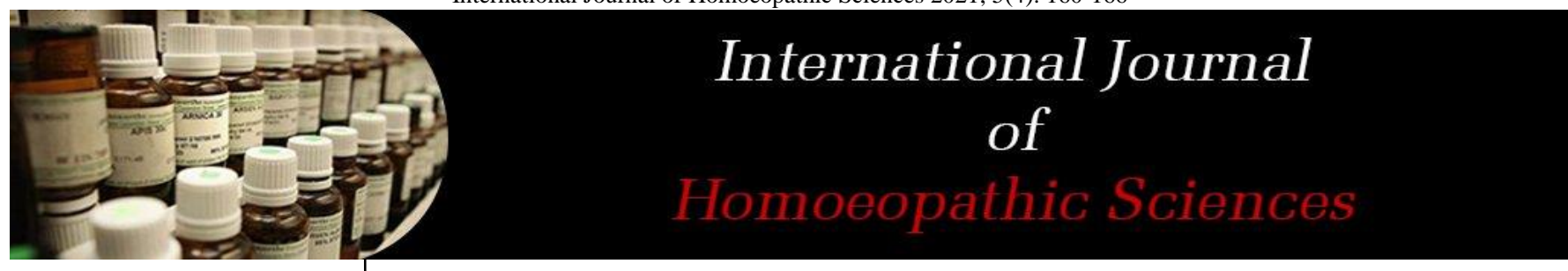

E-ISSN: $2616-4493$ P-ISSN: 2616-4485 www.homoeopathicjournal.com IJHS 2021; 5(4): 160-166 Received: 16-07-2021 Accepted: 03-09-2021

Dr. Sumalatha $\mathbf{P}$ M.D. (Homoeopathic Pharmacy).

Dr. Dastagiri $\mathbf{P}$ Research officer/Scientist-I, National Homoeopathy Research Institute in Mental Health, Under Central Council for Research in Homoeopathy, Ministry of AYUSH, Kottayam, Kerala, India

\section{The effectiveness of the ferula asafoetida in the treatment of dyspeptic disorders}

\author{
Dr. Sumalatha $P$ and Dr. Dastagiri $P$
}

DOI: https://doi.org/10.33545/26164485.2021.v5.i4c.465

\title{
Abstract
}

Background and Objective: Dyspepsia is a common condition observed in daily clinical practice. Traditionally, for many centuries, Ferula Asafoetida has been used for various gastric disturbances in physiological doses. This study is an effort to understand its effectiveness in Dyspeptic disorders on a homoeopathic basis.

Methods: A prospective, observational, non-randomised, and non-controlled study was conducted at Government Homoeopathic Medical College, Kadapa, Andhra Pradesh, from 2018 to 2019. A purposive sampling technique was used to enroll 30 patients (15 males and 15 females) complaining of heartburn and regurgitation of food of all age groups by the Esophagogastroduodenoscopy diagnosis and differentiating the other causes of illness to fit in the study. Ferula Asafoetida was prescribed in $30 \mathrm{cH}$ and $200 \mathrm{cH}$ high dilution in repeated doses according to the Homoeopathic posology. The assessment was done by establishing the Dyspepsia questionnaire and Global Overall Symptom (GOS) scale before and after the intervention at baseline and after the one year.

Results: At 29 degrees of freedom, the 5\% significant limit of ' $t$ ' is 2.05 . The observed ' $t$ ' value is 14.62. Hence, Asafoetida yielded a significant effect in the treatment of Dyspeptic disorders.

Limitations: It includes that we could not perform the urea breath test, stool and biopsy of the stomach tissue to diagnose the H.pylori infection, a lack of control arm and used purposive sampling method for enrolling patients to prescribe Asafoetida.

Conclusion: This study has shown optimistic results regarding the usefulness of Ferula Asafoetida in the treatment of Dyspeptic disorders. However, further randomised controlled trials with long-term follow-ups need to be conducted for definite conclusions.

Keywords: Dyspepsia, ferula asafoetida, dyspepsia questionnaire and global overall symptom (GOS)

\section{Introduction}

The term dyspepsia (Greek "dys" means bad, "pepsis" means digestion) and is popularly known as Indigestion. It was first recorded in the mid- $18^{\text {th }}$ century, and since it has been extensively used ${ }^{[1]}$.

Dyspepsia, an umbrella term for many gastrointestinal symptoms. The spectrum of this disease symptom localized to the epigastric region and the flanks with pain and burning (60 to $70 \%)$, feeling bloated after a meal $(80 \%)$, distension in the epigastric region $(80 \%)$, early satiation (60 to $70 \%)$, nausea $(60 \%)$, and vomiting $(40 \%)^{[2]}$.

Globally, the prevalence of dyspepsia has been reported at $21 \%$, though with a geographical and methodological variation ${ }^{[3]}$. In India, that 7.6 to $49 \%$ is estimated from the limited available Data. A research study conducted in Uttar Pradesh, India, related to dyspepsia and socioeconomic classes and results were denoted that this illness mainly observed in upper (16.7\%), upper-middle (15.1\%), lower-middle (22\%), upper-lower (22.2\%), and lower (24\%), mainly after 18 years old age-groups ${ }^{[4]}$.

The immense burden of this illness, including its high population prevalence and impact on quality of life, leads to over $\$ 14$ billion annually in direct care costs, including the absenteeism to their regular duties, which impose an economic burden on the health care system $^{[5]}$.

The primary cause of this clinical condition is Helicobacter pylori (H. pylori) infection, gastro-oesophagal reflux (with or without esophagitis), medications, functional dyspepsia, chronic peptic ulcer disease (PUD) and malignancy. Less likely causes include pancreatic or hepatobiliary tract disease, motility disorders, celiac disease, infiltrative diseases of the stomach (e.g., eosinophilic gastritis, Crohn's disease, Sarcoidosis), Intestinal angina, Small Intestine Bacterial Overgrowth (SIBO), Irritable Bowel Syndrome (IBS), Metabolic disturbances (e.g., hypercalcemia, heavy metal), diabetic radiculopathy, hernia and abdominal wall pain ${ }^{[6]}$.

Corresponding Author: Dr. Sumalatha $\mathbf{P}$ M.D. (Homoeopathic Pharmacy). 
Further, Psychological distress, Spicy food habit and increased consumption of coffee may be associated with an increase in dyspepsia symptoms and $\mathrm{H}$. pylori infection ${ }^{[7,8,}$ $9,10]$.

The Risk factors include psychological comorbidity, anxiety, chewing tobacco, aerated soft drinks, tea/coffee, disturbed sleep pattern, acute gastroenteritis, smoking, nonsteroidal anti-inflammatory drugs (NSAIDs), and Helicobacter pylori infection. The pathophysiology remains incompletely understood if it is probably related to disordered communication between the gut and the brain, leading to motility disturbances, visceral hypersensitivity and alterations in gastrointestinal microbiota, mucosal and immune function, psychological disturbances, environmental factors, H. pylori and Central Nervous System processing ${ }^{[7,11,12]}$.

Plants have been a constant source of drugs, and recently, much emphasis has been placed on finding novel therapeutic agents from medicinal plants. As a result, many people have a preference to use medicinal plants rather than chemical drugs for their minor illnesses. Ferula Asafoetida Linn: Asafoetida, the gum resin prized as a condiment in India and Iran, is obtained chiefly from the plant Ferula asafoetida. The Latin name ferula means "carrier" or "vehicle". As a Latinized form of Farsi as "resin", Latin foetidus means "smelling, fetid" [13].

From ancient times to the present day, this plant can be used as a domestic/kitchen remedy in different clinical symptoms like bronchitis, hysteria, nervous conditions, asthma, whooping cough, infantile pneumonia, flatulent colic, lowered blood pressure and as a sedative. Moreover, it is widely used in India to prepare certain dishes and medicine in the Indian system of medicine like Ayurveda ${ }^{[13]}$.

Many studies have proven the Asafoetida's relaxing effect on the gastrointestinal smooth muscle; these include the blocking action on excitatory pathways such as histaminergic, cholinergic, or mimicking the action of an inhibitory system like adrenergic, purinergic, GABAergic, and /or nitric oxide. In addition, pharmacological studies have also established the antiviral, antimicrobial, antidiabetic, antioxidant, and gastro-protective activities of the Asafoetida ${ }^{[14]}$.

Burt W.H., in his Physiological Materia Medica, explained the pathophysiological action of Asafoetida mostly on the Muscular system, Glandular system, and Mucous membrane through Central Nervous System. On the Stomach and Abdomen- it produces excessively fetid eructations, smelling like garlic. Great accumulation of gas in the stomach and bowels; the gas constantly presses upward, with belching. Feeling of strong pulsation in the epigastrium; painful hiccough, nausea, vomiting, colic. Meteriosm of the stomach, great tension and difficult eructation; gone, empty feeling in stomach pit, pulsation, and fainting. Pain in stomach, during upward along the oesophagus. Flatulent colic with abdominal pulsation and great distension with gas: hysterical. Watery, green or brown stools, with disgusting odour ${ }^{[15]}$.

However, due to the extensive affinity towards the dyspeptic condition and no clinical evaluations have been reported on the therapeutic effect of Asafoetida in treating dyspeptic disorders, particularly in Homoeopathy. Hence, this research study's primary aim and objective are to explore the effectiveness of the Ferula Asafoetida in treating dyspeptic disorders.

\section{Aim}

The main aim of this study is to ascertain the effectiveness of Ferula Asafoetida in the treatment of dyspeptic disorders.

\section{Objectives}

The main objective of this study is to study the effectiveness of Ferula asafoetida in $30 \mathrm{cH}$ and $200 \mathrm{cH}$ potency clinically.

\section{Materials and Methods Study Design}

The study is a Prospective, Observational, non-randomised, and non-controlled study.

\section{Study Population \\ Study site}

This study was undertaken on patients attending out-patient and In-patient departments of Government Homoeopathic Hospital, Kadapa, Andhra Pradesh, India, from 2018 to 2019. This research study was conducted after getting the permission and approval from the Guide, Principal of the Institute, Superintendent of the Hospital, and NTR University of Health Sciences, Vijayawada, Andhra Pradesh, India, under the partial submission of the Postgraduate thesis. The sample size of 30 cases was selected, and the sample selection was made at the study setting based on inclusion and exclusion criteria as stated below.

\section{Inclusion criteria}

1. Patients of all age groups and both sexes with symptoms of diseases characterised by functional dyspepsia, peptic ulcers, gastritis symptoms, and having clinical symptoms similar to the Asafoetida.

2. Patients diagnosed with Functional Dyspepsia, Peptic Ulcer, and Gastritis by Esophagogastroduodenoscopy. Cases under the scope of Homoeopathy and relevant to study are included. Cases having similar symptoms to Asafoetida therapeutics are included. Subject willing to give written informed consent by participants and parents/guardians under 18 years.

\section{Exclusion criteria}

1. Complicated signs include tenderness, muscle guarding or rigidity, peristaltic waves, occult blood in the stool.

2. Patients with alarm features in dyspepsia include weight loss, hematemesis and melaena, Anemia, dysphasia, vomiting, and palpable abdominal mass.

3. Cases other than functional dyspepsia, peptic ulcers, gastritis.

4. Positive family history of malignancy.

5. Persons suffering simultaneously with any other chronic debilitating disorders and inevitably on conventional medication are excluded.

Study period: The study was conducted for a minimum of six months to a maximum of one year. Follow up all the cases were reviewed once in fifteen, thirty days, and all cases were followed for a minimum of six months to a maximum of one year.

\section{Results}

This study needs a minimum of thirty patients, although screened 100 cases and 30 patients were enrolled. However, no dropouts and the data of all 30 cases are represented. 


\section{Clinical protocol}

1. A detailed case history was recorded in a predesigned case taking proforma. Factors that lead to dyspepsia such as alcohol consumption, smoking, irregular sleeping, and dietary habits were also mentioned, enabling us to give about the symptomatology, diagnosis, and treatment. Esophagogastroduodenoscopy (EGD) was an invasive procedure and cost bearing only for diagnosis purposes. Outcome evaluated by providing the Dyspepsia questionnaire and GOS.

2. The history was taken in detail regarding past history, treatment history, family history, mental generals, physical generals and life space investigation to arrive at a probable cause of the disorder.

3. Potency was selected based on susceptibility - age, sex, constitution, duration, seat and stage of the disease.

4. EGD was done in patients who agreed to the investigation to distinguish between non-ulcerative and ulcerative dyspepsia or if previous reports are considered.

\section{Outcome measures}

- The treatment results were assessed based on the Dyspepsia questionnaire and Global Overall Symptom (GOS) scale before and after treatment. The observations and results are analysed based on statistical methods and calculations.

- If the patient was under Modern Medicine/Allopathic drugs, they were stopped at a time or gradually tapering the dose depending upon the severity of the complaints.

\section{Management}

- Appropriate general management techniques, including changes in diet and regimen, lifestyle modifications, his/her eating patterns, to avoid high consumption tea/ coffee or alcohol advised depending on the case.

- Patients were also advised to practise relaxation techniques, meditation, and physical exercises according to the necessity of the case.

\section{Treatment and follow UP}

- Two higher dilutions were used, namely $30 \mathrm{cH}$ and $200 \mathrm{cH}$. Therefore, 15 cases out of 30 were given $30 \mathrm{cH}$ higher dilution, and 15 were given $200 \mathrm{cH}$ high dilution based on the patient's susceptibility.

- All the cases were reviewed once in 7, 15 days followed for a minimum of 6 months and a maximum of one year.

- A successive higher dilution was administered whenever a selected or given high dilution failed to bring out the favourable result.

\section{Observation and Results}

1. Representation of data according to the age group. (Fig.1).

2. Representation of data according to the gender of the patients (Fig.2).

3. Representation of data according to the economic
Status (Fig.3).

4. Representation of data according to the Habits (Fig.4)

5. Representation of data according to the cause of the illness (Fig.5).

6. Representation of the data according to common presenting complaints (Fig.6)

7. Representation of the data according to the diagnosis (Fig.7)

8. Representation of the data about the effectiveness of Asafoetida in dyspepsia symptoms (Fig.8)

9. Representation of the data about the effectiveness of Asafoetida concerning Potency (Fig.9).

10. Representation of the data about GOS scale before and after (Fig.10).

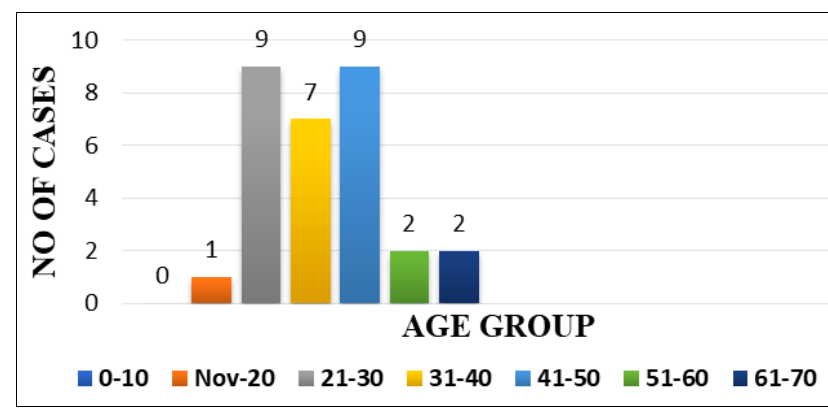

Fig 1: Incidence of age group

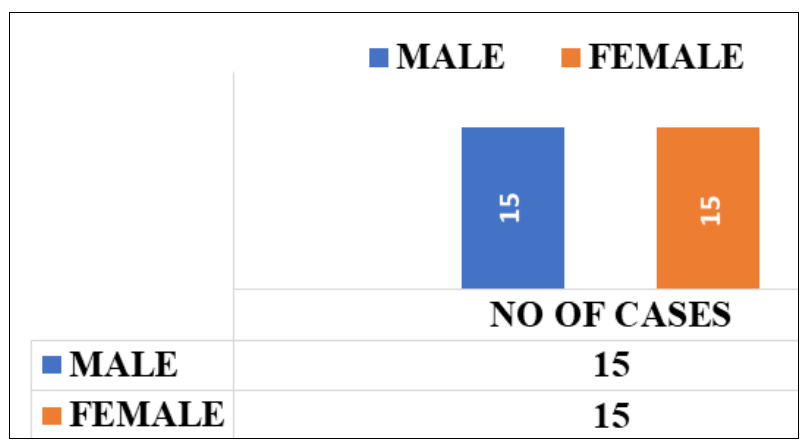

Fig 2: Distribution of cases in relation to gender

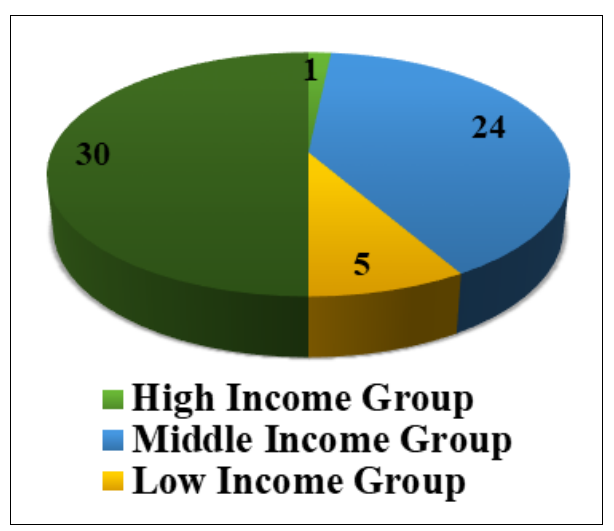

Fig 3: Incidence of socio-economic status 


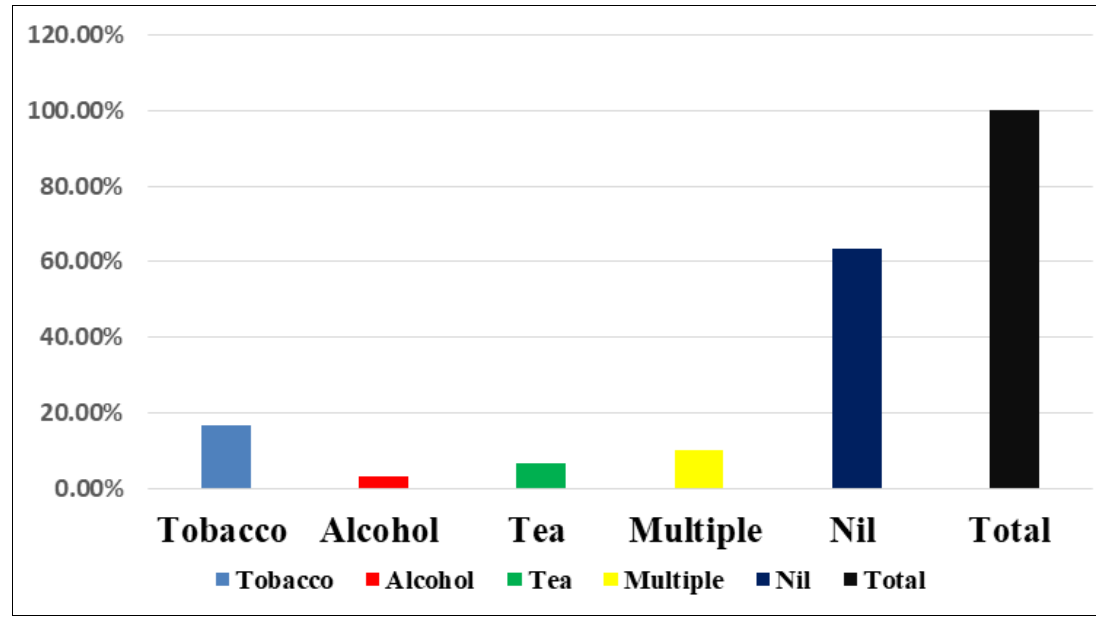

Fig 4: Incidence related to habits

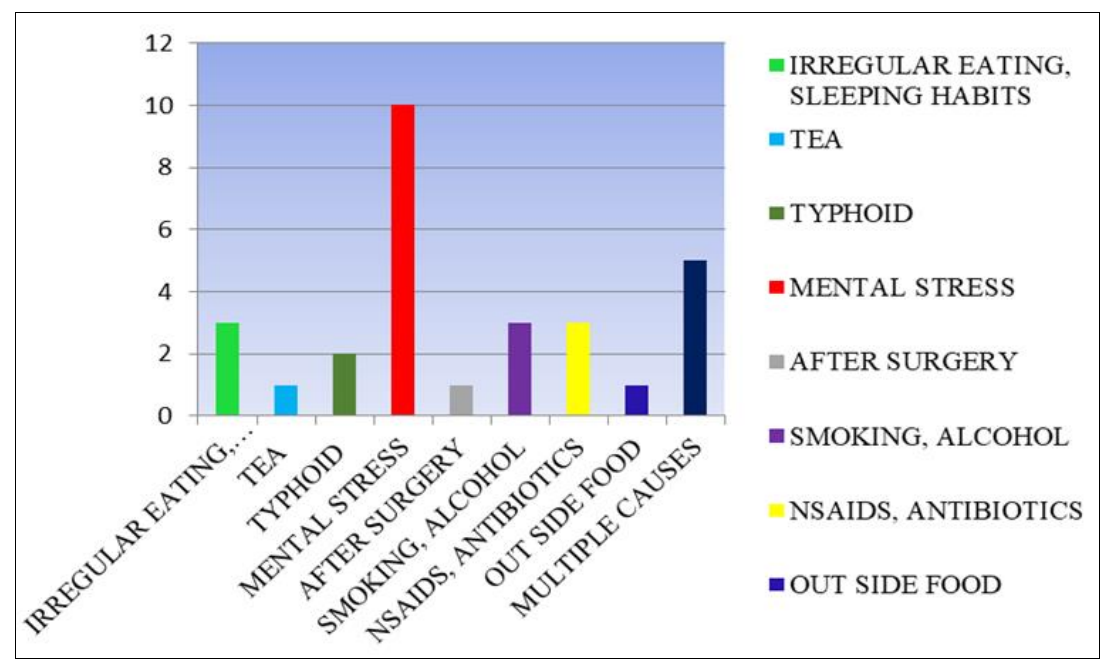

Fig 5: Incidence related to cause

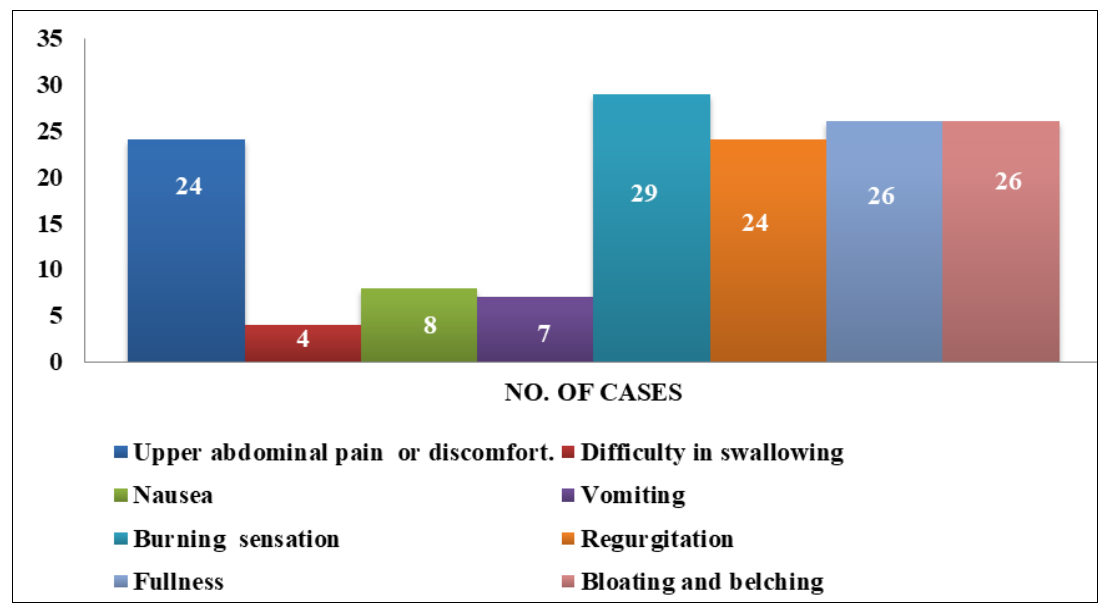

Fig 6: Incidence of common presenting complaints 


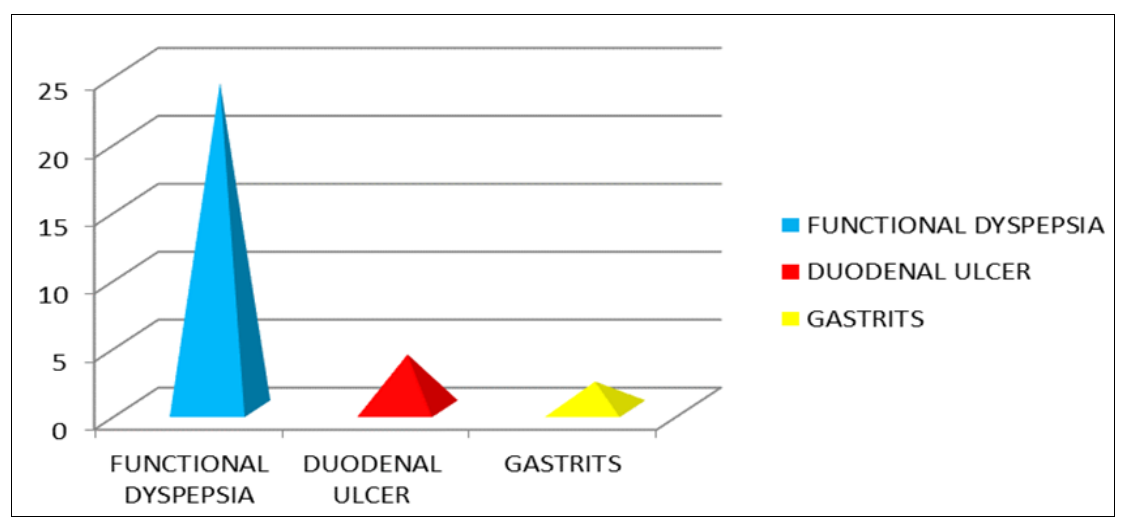

Fig 7: Incidence related to diagnosis

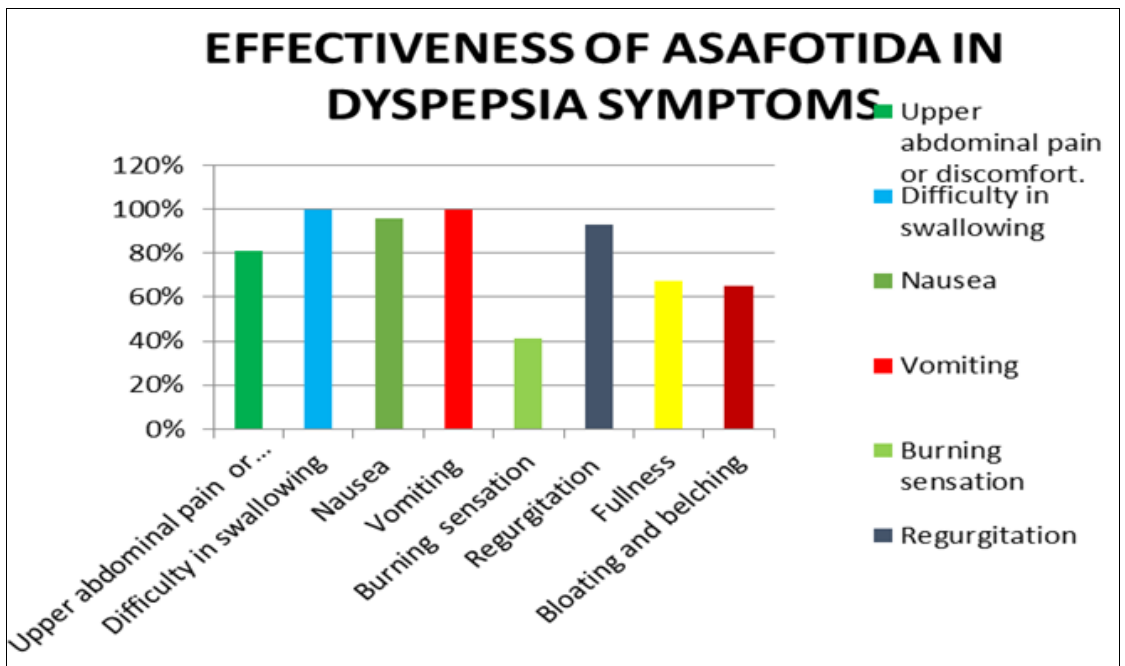

Fig 8: Effectiveness of asafoetida in dyspepsia symptoms

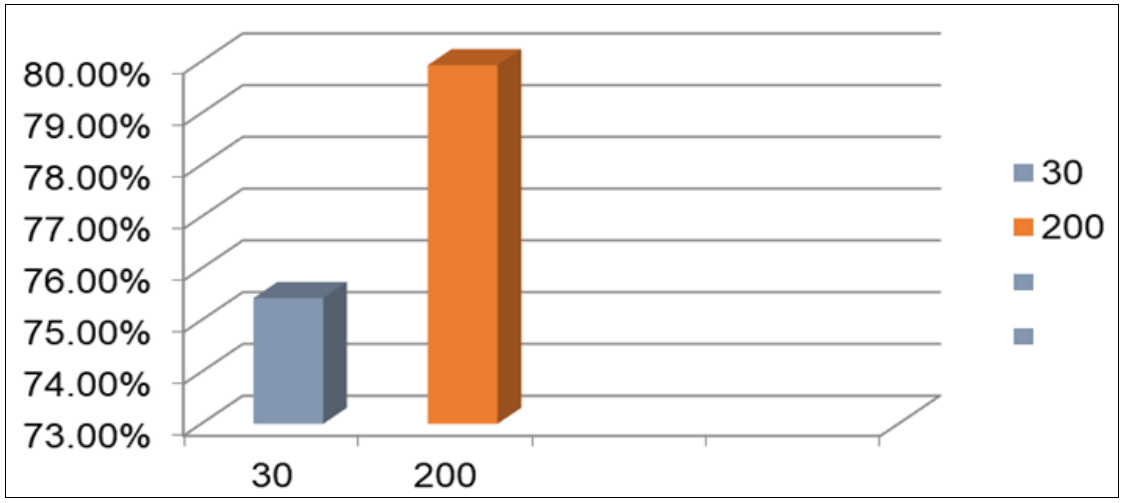

Fig 9: Efficacy of asafoetida related to ITS potency

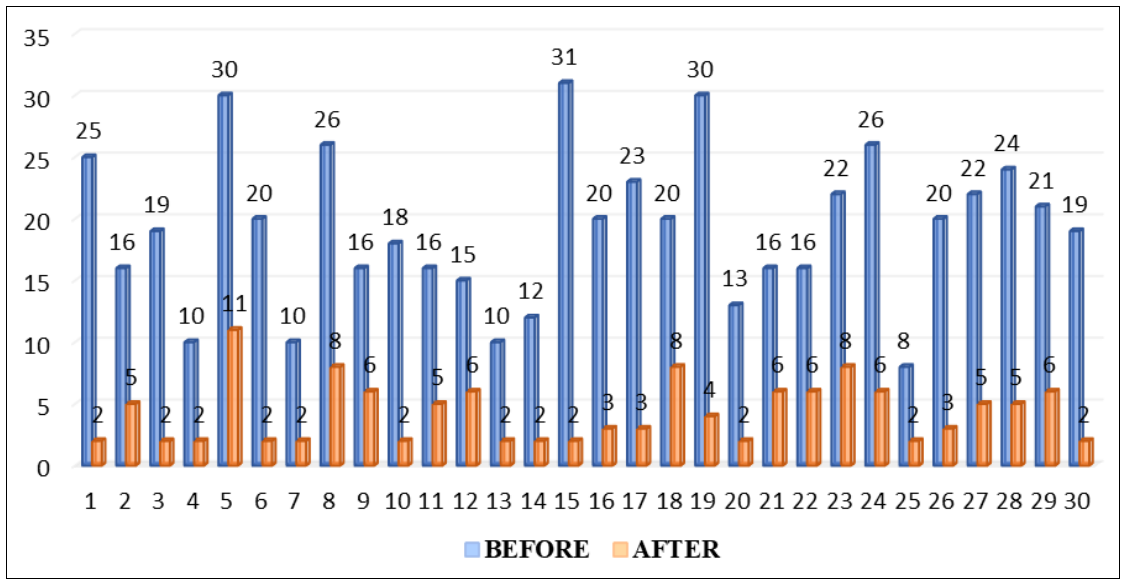

Fig 10: GOS scale 


\section{Results and Discussion}

1. Incidence of age group: In this study of out of 30 cases, 30\% (9) patients reported in 21-30 and 41-50 age group, followed by $23.33 \%$ (7) patients in 31-40, $6.66 \%$ (2) patients in each 51-60 and 61-70, and significantly less percentage, i.e., 3.33\%(1) patient in between 11-20 age grope population.

2. Gender of the patients: Out of 30 cases, males (15), i.e., $50 \%$, and females (15), i.e., $50 \%$. So that means the overall incidence of dyspeptic disorders is equal in males and females.

3. Socioeconomic Status: In this study, the highest no. of cases, 24, i.e., $80 \%$ are recorded in the middle-income group, and 5 cases, i.e. $16.66 \%$ in the low-income group, and only 1 case $3.33 \%$ was recorded in the highincome group. Thus, the highest number of cases, 24 $(80 \%)$, are recorded in the middle-income group; this observation is close to the existing literature.

4. Habits: The highest no. of cases 19, (63.33\%) are recorded having no habits, and 5 cases, i.e., $16.66 \%$ tobacco chewing and smoking, 3 cases, i.e., $10 \%$ multiple habits, and 2 cases, i.e., $6.66 \%$, having tea habit, and 1 case, i.e., $3.33 \%$ having alcohol habit in total 30 cases.

5. Cause of the Dyspepsia: Out of 30 cases, 10 cases $(33.33 \%)$ are due to mental stress, and 5 cases $(16.66 \%)$ are due to multiple causes, and 3cases $(10 \%)$ each due to irregular eating, and sleeping, smoking and alcohol habits, using NSAIDs, and antibiotics. Of 2 cases due to typhoid, i.e., $6.66 \%$, and 1 case each due to tea drinking, eating outside food, after surgery, due to unknown cause, i.e., $3.33 \%$.

6. Common Presenting Complaints: In this study of 30 cases of non-ulcer dyspepsia draws few observations regarding the incidence of symptomatology; the Burning sensation is the highest recorded symptom of dyspepsia in 30 cases 29 cases $(96.67 \%)$, Bloating and belching, Fullness 26 cases (86.67\%), and Regurgitation, Upper abdominal pain or discomfort 24 cases (80\%), and Nausea 8 cases (26.67\%), and vomiting 7 cases $(23.33 \%)$, and difficulty in swallowing 4 cases $(13.33 \%)$.

7. Diagnosis: Out of 30 cases, most cases 24 , i.e., $80 \%$ were Functional Dyspepsia, and 4 cases, i.e., $13.33 \%$, had duodenal ulcers and 2 cases, i.e., 6.66\% having gastritis. This finding is in equivalence with the current understanding of the incidence of Non-ulcer Dyspepsia. Furthermore, this observation indicates that dysmotility-like dyspepsia is more common than ulcerlike or unspecified Dyspepsia of Rome criteria.

8. Effectiveness of Asafoetida in Dyspepsia symptoms: It has been observed that Asafoetida is highly effective in treating difficulty in swallowing and vomiting $(100 \%)$, nausea $(95.83 \%)$, regurgitation (93\%), abdominal pain or discomfort $(81 \%)$, the fullness of abdomen (67.3\%), Bloating and belching, (64.94\%), Burning sensation, (41.33\%). This shows that the result of this work is more encouraging in treating dyspeptic disorders.

9. Effectiveness of Asafoetida concerning Potency: Among the study group of 30 patients, the exciting part of this critical study was regarding the Potency of Asafoetida, which gave a good percentage of relief. When the high dilution was observed, the Asafoetida was highly effective in $200 \mathrm{cH}$ high dilution, i.e., $79.93 \%$, and $30 \mathrm{cH}$ high dilution $(75 \%)$.

10. Observation of GOS before and after the intervention of Asafoetida shows the significant improvement in the dyspeptic symptoms without any noticeable adverse events in all thirty cases.

Statistical Analysis: Statistical analysis was done using paired t-test and f test. At 29 degrees of freedom, the 5\% significant limit of ' $t$ ' is 2.05 . The observed ' $t$ ' value is 14.62. So null hypothesis was rejected, and the Alternative hypothesis was accepted. Thus, Asafoetida produced a significant effect in the treatment of dyspeptic disorders. The calculated standard deviation $\mathrm{S}_{1} 30 \mathrm{cH}$ high dilution is 27.03 is less than the estimated standard deviation $S_{2}$ of $200 \mathrm{cH}$ high dilution is 128.02 . So, $30 \mathrm{cH}$ high dilution is consistent with $200 \mathrm{cH}$ high dilution.

\section{Conclusion}

Dyspepsia is a significant gastrointestinal tract disease; unlike IBS, people of any age and sex can suffer from this illness. Nowadays, many people suffer from dyspeptic disorders due to various causes like altered diet or living patterns, high consumption of stimulants like tea/coffee, carbonated drinks, alcohol, abuse or adverse effects of NSAIDs, and inevitable psychological distress may provoke this illness. The clinical diagnosis was made based on eight clinical symptoms, i.e., pain or discomfort in the abdomen, difficulty swallowing, nausea, vomiting, burning sensation, regurgitation, fullness, bloating and belching, confirmed with EGD procedure, and severity of the symptoms assessed by Dyspepsia symptom score, GOS before and after the intervention the Asafoetida.

According to the definition of dyspepsia, the percentage of the spectrum of the symptoms are similar to this study, as like burning (96.6\%), bloating, belching after a meal (86.67\%), upper abdominal pain and discomfort (80\%), nausea and vomiting (26.67\% and $23.33 \%)$ respectively.

It has been observed that the incidence of this illness was more in the middle-income group $(80 \%)$ which contrasting the citing literature conducted in India, maybe the awareness of Homoeopathy more in the educated population.

In this study, the causes and risk factors are explicitly resemblances to the citing literature, like psychological distress/stress is the most prominent cause, followed by multiple causes, irregular eating habits, consumption of smoking and alcohol, and more minor causes are like tea/coffee, infections(Typhoid), after surgery, NSAIDs, and outside food.

In all patients, a significant decrease in the symptom score from the first follow-up assessment was seen. Furthermore, the improvement continued in all cases in the dyspepsia questionnaire score and GOS scale also.

Out of 30 cases of Non-Ulcer (Functional), Ulcerative, and Gastritis Dyspepsia, the efficacy of Asafoetida was critically evaluated, mostly $200 \mathrm{cH}$ higher dilution shown the better results compared to $30 \mathrm{cH}$ higher dilution.

The limitation of this study is that we could not perform the urea breath test, stool and biopsy of the stomach tissue to diagnose the H.pylori infection due to non-cooperation from the participants, a lack of control arm and used purposive sampling method for enrolling patients to prescribe Asafoetida. Nevertheless, these favourable results will lead to randomised controlled studies with a larger sample size to 
validate the Ferula Asafoetida in treating dyspeptic disorders.

Sourer of funding: None.

\section{Conflict of interest: None.}

\section{Acknowledgement}

I, sincerely thankful to Dr. D. Babu Balaji Prakash, professor and Head Of the Department of Homoeopathic Pharmacy, and superintendent of Govt Homoeopathic Medical Hospital, Kadapa, and Dr. G. Surender Reddy, Principal, Govt. Homoeopathy Medical College, Kadapa, Andhra Pradesh, for their constant support in this study. Moreover, finally, I am thankful to all patients who trusted me and without whom I could not have completed this study.

\section{References}

1. Basandra S, Bajaj D. Epidemiology of Dyspepsia and irritable bowel syndrome (IBS) in medical students of Northern India. Journal of clinical and diagnostic research: JCDR 2014;8(12):JC13. Available from: https://www.ncbi.nlm.nih.gov/pmc/articles/PMC43162 $80 /$

2. Talley NJ, Vakil N. Practice Parameters Committee of the American College of Gastroenterology. Guidelines for the management of dyspepsia. American Journal of Gastroenterology 2005;100(10):2324-37. Available from: https://pubmed.ncbi.nlm.nih.gov/16181387/.

3. Futagami S, Yamawaki H, Agawa S, Higuchi K, Ikeda $\mathrm{G}$, Noda $\mathrm{H}$ et al. New classification Rome IV functional dyspepsia and subtypes. Translational gastroenterology and hepatology 2018, 3. Available from:

https://www.ncbi.nlm.nih.gov/pmc/articles/PMC61820 $37 /$

4. Ghoshal UC, Singh R. Functional dyspepsia: the Indian scenario. Available from: https://www.researchgate.net/profile/Rajan-Singh14/publication/230728635_functional_dyspepsia_the/li nks/0fcfd5039095629b8a000000/functional-dyspepsiathe.pdf

5. Madisch A, Andresen V, Enck P, Labenz J, Frieling T, Schemann M. The diagnosis and treatment of functional dyspepsia. Deutsches Ärzteblatt International 2018; 115(13):222. Available from: https://www.ncbi.nlm.nih.gov/pmc/articles/PMC59384 38/

6. Bangamwabo JB, Chetwood JD, Dusabejambo V, Ntirenganya C, Nuki G, Nkurunziza A et al. Prevalence and sociodemographic determinants of dyspepsia in the general population of Rwanda. BMJ open gastroenterology 2020;7(1):e000387. Available from: https://bmjopengastro.bmj.com/content/bmjgast/7/1/e00 0387.full.pdf.

7. Tack J, Talley NJ. Functional dyspepsia-symptoms, definitions and validity of the Rome III criteria. Nature Reviews Gastroenterology \& hepatology 2013;10(3):134-41. Available from: https://www.nature.com/articles/nrgastro.2013.14.

8. Harmon RC, Peura DA. Evaluation and management of Dyspepsia. Therapeutic advances in gastroenterology 2010;3(2):87-98. Available from: https://journals.sagepub.com/doi/pdf/10.1177/1756283

\section{X09356590.}

9. Verma A. The study of risk factors associated with dyspepsia. International Journal of Biomedical and Advance Research 2016;7(9):468-471. Available from: https://ssjournals.com/index.php/ijbar/article/view/3612 12520.

10. Barry S, Dinan TG. Functional dyspepsia are psychosocial factors of relevance. World Journal of Gastroenterology: WJG 2006;12(17):2701. Available from:

https://www.ncbi.nlm.nih.gov/pmc/articles/PMC41309 $78 /$.

11. Ford AC, Mahadeva S, Carbone MF, Lacy BE, Talley NJ. Functional Dyspepsia. The Lancet. 2020 Oct 10.Available from: Ford AC, Mahadeva S, Carbone MF, Lacy BE, Talley NJ. Functional Dyspepsia. The Lancet 2020.

12. Abhyudaya V, Deepika V, Pooja B, Akhil BTO. Study The Etiology And Symptoms Associated With Dyspepsia In A Tertiary Care Hospital. Natl JIntegr Res Med 2016;7(6):97-100.

13. Mahendra P, Bisht S. Ferulaasafoetida: Traditional uses and pharmacological activity. Pharmacognosy reviews 2012;6(12):141. Available from: https://www.ncbi.nlm.nih.gov/pmc/articles/PMC34594 $56 /$.

14. Mala KN, Thomas J, Syam DS, Maliakel B, Krishnakumar IM. Safety and efficacy of Ferulaasafoetida in functional dyspepsia: a randomised, double-blinded, placebo-controlled study. EvidenceBased Complementary and Alternative Medicine 2018. Available from: https://www.hindawi.com/journals/ecam/2018/4813601 /

15. Burt WH. Physiological Materia Medica, Fifth Edition, Gross \& Delbridge Co 1896, 139-142. 